\title{
Prevalence and management of anaemia in patients with non-myeloid cancer undergoing systemic therapy: a Spanish survey
}

\author{
J. L. Steegmann · J. M. Sánchez Torres • \\ R. Colomer · Á. Vaz • J. López • I. Jalón • \\ M. Provencio · A. González-Martín · M. Pérez
}

Received: 30 July 2012/ Accepted: 1 October 2012/Published online: 19 December 2012

(C) The Author(s) 2012. This article is published with open access at Springerlink.com

\begin{abstract}
Background The present study aimed to provide updated data on anaemia prevalence and management in cancer patients undergoing systemic therapy in Spain.

Methods This was a multicenter, observational, crosssectional study performed in 2008. Eligible patients were $\geq 18$ years, with non-myeloid malignancies treated with systemic therapy [chemotherapy (CT), hormonal therapy
\end{abstract}

\section{J. L. Steegmann $(\square)$}

Servicio de Hematología, Hematology Department, Instituto de Investigación Sanitaria (IIS-IP), Hospital Universitario de la Princesa, Diego de Leon, 62, 28006 Madrid, Spain

e-mail: jlsteegmann.hlpr@salud.madrid.org

J. M. Sánchez Torres

Servicio de Oncología Médica, Hospital 12 de Octubre,

Madrid, Spain

Present Address:

J. M. Sánchez Torres

M.D. Anderson Cancer Center, Madrid, Spain

R. Colomer · A. González-Martín

Servicio Oncología Médica, M.D. Anderson Cancer Center,

Madrid, Spain

Á. Vaz · J. López

Departamento de Hematología, Hospital Ramón y Cajal,

Madrid, Spain

\section{Jalón}

Departamento de Hematología, Clínica Ruber, Madrid, Spain

\section{Provencio}

Departamento de Oncología Médica, Hospital Puerta de Hierro, Madrid, Spain

\section{Pérez}

Servicio de Oncología, Hospital Universitario de la Princesa, Madrid, Spain or immunotherapy]. Anaemia was defined according to WHO as haemoglobin $(\mathrm{Hb})<12 \mathrm{~g} / \mathrm{dL}$.

Results The study included 214 patients with a median age of 63 years (range 20-91), $58 \%$ women, $73 \%$ with solid tumours, and $79 \%$ with advanced disease. CT was used in $91 \%$ of patients ( $26 \%$ with platinum compounds), hormonal therapy in $8.5 \%$, and immunotherapy in $8.5 \%$. In our study, $48.1 \%$ of patients [95\% confidence interval (CI) 45.2-58.6] showed anaemia (31\% symptomatic): $42.0 \%$ mild $(10 \leq \mathrm{Hb} \leq 11.9 \mathrm{~g} / \mathrm{dL}), 5.6 \%$ moderate $(8 \leq \mathrm{Hb} \leq 9.9 \mathrm{~g} / \mathrm{dL})$, and $0.5 \%$ severe $(\mathrm{Hb}<8 \mathrm{~g} / \mathrm{dL})$. A higher prevalence was observed in patients treated with CT (51 vs. $20 \%, p=0.01$ ), platinum-based CT (70 vs. $47 \%, p=0.01$ ) or palliative CT (61 vs. $39 \%, p=0.003$ ). Anaemia was also more frequent in patients with more than three lines of CT (83\%) and in the fourth or subsequent CT cycle (58\%). Management in the previous 4 weeks in patients with anaemia was: $62 \%$ did not receive treatment (92\% mild), $24 \%$ received erythropoiesis-stimulating agents (ESAs), $14 \%$ received iron and $8.7 \%$ received transfusion.

Conclusions In Spanish hospitals, about half of patients with non-myeloid malignancies undergoing systemic therapy fulfilled anaemia criteria ( $87 \%$ mild). Approximately two-third of patients with anaemia do not receive specific treatment and ESA use is below current guidelines.

Keywords Anaemia - Darbepoetin alfa - Chemotherapy · Solid tumours · Haematological malignancies · Transfusion

\section{Introduction}

Most cancer patients suffer anaemia during the course of the disease or the treatment, in particular those patients 
receiving myelosuppressive chemotherapy [1]. Severe anaemia $(<8 \mathrm{~g} / \mathrm{dL})$ can lead to the onset of cardiovascular and respiratory symptoms, such as tachycardia, hypotension and dyspnoea, although less severe anaemia can also produce a range of symptoms such as fatigue, exercise intolerance, decreased appetite and reduced general welfare [2]. In addition, anaemia has been shown to influence the evolution of disease, increasing the risk of progression and decreasing overall survival $[3,4]$.

Significant progress has been made in the prevention and management of chemotherapy-induced anaemia. Current therapeutic options include iron supplementation, administration of erythropoiesis-stimulating agents (ESAs) and blood transfusion. Several guidelines have been published with specific recommendations [5-7], like the 2007 European Organization for Research and Treatment of Cancer (EORTC) guidelines [6]. The European Cancer Anaemia Survey (ECAS) [8], the first major epidemiological study on anaemia conducted in 2001, revealed a high prevalence and incidence, and highlighted that many patients (some of them with haemoglobin $[\mathrm{Hb}]<10 \mathrm{~g} / \mathrm{dL}$ and/or symptomatic anaemia) received no specific treatment. Since then, some studies in particular countries like France [9], Germany [10] and Belgium [11], have provided updated and country-specific information on anaemia management and fulfilment of guidelines. In the Spanish context, there is no recent data available in this field. This study aims to provide accurate and relevant information on the prevalence and patterns of treatment of anaemia in Spanish cancer patients treated with systemic therapy with or without radiation therapy in the clinical practice.

\section{Patients and methods}

This was an observational, multicenter, cross-sectional study in 21 Spanish hospitals. We consecutively included all patients who attended the clinic during a particular day of the week from May 19 to May 23, 2008 (to be chosen by each site according to their availability), and fulfilled selection criteria: age $\geq 18$ years; patients diagnosed with non-myeloid tumour (except for myelodysplastic syndromes), undergoing treatment with systemic therapy (CT, hormone therapy or immunotherapy), with or without radiation therapy; patients who had received the last cycle of treatment within the previous 4 weeks; patients who had a blood test (including $\mathrm{Hb}$ value) performed on the date of the visit or within the past $72 \mathrm{~h}$; non-hospitalized patients. The protocol was approved by an independent ethics committee, and all patients gave their written informed consent before enrolment.
Data on clinical characteristics, type of cancer, treatment for anaemia and $\mathrm{Hb}$ levels were collected for the baseline visit and for the past 4 weeks. We defined the degree of anaemia according to World Health Organization (WHO) as follows: mild anaemia, $\mathrm{Hb}$ between 11.9 and $10 \mathrm{~g} / \mathrm{dL}$; moderate anaemia, Hb between 9.9 and $8 \mathrm{~g} / \mathrm{dL}$; severe anaemia, $\mathrm{Hb}<8 \mathrm{~g} / \mathrm{dL}$.

Statistical analysis was descriptive. The prevalence of anaemia in the entire study population and in specific subgroups (by type and stage of tumour, age category, sex, presence or absence of symptoms and type and characteristics of systemic therapy) was described. Treatments for anaemia received in the 4 weeks prior to inclusion and provided on that day were also described (no treatment, transfusion, iron supplements or vitamins, ESAs). We performed an exploratory analysis to analyze the relationship between patient characteristics or treatment and the presence of anaemia. For qualitative variables, the relationship was assessed using Chi Square tests (or Fisher's exact test if it was applicable), and for quantitative variables, using Student's $t$ tests. Statistical analyses were performed with the $\mathrm{SAS}^{\circledR}$ package-version 9.0 (SAS Institute, Cary, NC, USA).

\section{Results}

\section{Study population}

The study included 214 patients with a median age of 63 years (range 20-91), $58 \%$ women and $73 \%$ with solid tumours. The most common tumour types were breast (37.6\%), gastrointestinal $(23.6 \%)$ and lung cancer $(19.7 \%$ ). Most patients (91\%) were receiving CT (of which $26 \%$ received platinum compounds), $8.5 \%$ hormone therapy, and $8.6 \%$ immunotherapy (Table 1).

The main reason for the visit was $\mathrm{CT}$ administration $(74.8 \%)$, followed by routine follow-up visit $(25.7 \%)$, radiotherapy administration $(4.7 \%)$ and other reasons $(5.2 \%)$. The median time since diagnosis was 8.4 months (range 1.2-240).

Prevalence of anaemia

Overall, $48.1 \%$ of patients (95\% CI 45.2-58.6) had anaemia (of whom $13 \%$ had levels $<10 \mathrm{~g} / \mathrm{dL}$ and $31 \%$ were symptomatic) (Fig. 1).

Median $\mathrm{Hb}$ level in the overall sample was $12.0 \mathrm{~g} / \mathrm{dL}$ (range 7.4-16.1) (Table 2). The proportion of patients who reported symptoms of anaemia in the current visit was the same as in the previous 4 weeks. Only three patients with symptoms at the current visit did not have anaemia according to the laboratory test. 
Table 1 Characteristics of the patients and treatment administered

\begin{tabular}{|c|c|c|c|}
\hline & $\begin{array}{l}\text { Non-myeloid malignancies } \\
N=214\end{array}$ & & $\begin{array}{l}\text { Non-myeloid } \\
\text { malignancies } \\
N=214\end{array}$ \\
\hline Age (years), median (range) & $63(20 ; 91)$ & Chemotherapy, $n(\%)$ & $193(91.0)$ \\
\hline Women, $n(\%)$ & $124(57.9)$ & Adjuvant $^{\mathrm{c}}$ & $37(20.7)$ \\
\hline Reason for visit, $n(\%)$ & & Advanced stage ${ }^{c}$ & $142(79.3)$ \\
\hline Chemotherapy & $160(74.8)$ & Line of advanced stage, $n(\%)^{\mathrm{d}}$ & \\
\hline Monitoring visit & $55(25.7)$ & First & $76(53.9)$ \\
\hline Radiotherapy & $10(4.7)$ & Second & $37(26.2)$ \\
\hline Therapy (antiemetics...) & $5(2.3)$ & Third & $16(11.3)$ \\
\hline Treatment of complications & $1(0.5)$ & More than third & $12(8.5)$ \\
\hline RBC transfusion & $1(0.5)$ & Intention, $n(\%)^{\mathrm{e}}$ & \\
\hline Other reasons & $3(1.4)$ & Curative & $87(46.8)$ \\
\hline Time since diagnosis (years), median (range) & $0.7(0.1-20)$ & Palliative & $99(53.2)$ \\
\hline Primary tumour, $n(\%)$ & & Cycle number, median (range) & $4(1 ; 19)$ \\
\hline Solid tumour & $157(73.4)$ & Type of therapy, $n(\%)^{\mathrm{f}}$ & \\
\hline Breast & $59(37.6)$ & Monotherapy & $69(36.7)$ \\
\hline Gastrointestinal & $37(23.6)$ & Polychemotherapy & $119(63.3)$ \\
\hline Lung & $31(19.7)$ & Use of platinums, $n(\%)^{\mathrm{g}}$ & \\
\hline Other & $30(19.1)$ & With platinum & $40(25.8)$ \\
\hline Haematological tumour & $57(26.6)$ & Without platinum & $115(74.2)$ \\
\hline Lymphoma & $14(24.6)$ & Radiotherapy, $n(\%)^{\mathrm{h}}$ & $21(10.0)$ \\
\hline Myeloma & $31(54.4)$ & Hormonal therapy, $n(\%)^{\mathrm{i}}$ & $18(8.5)$ \\
\hline Other & $12(21.0)$ & Immunotherapy, $n(\%)^{\mathrm{j}}$ & $18(8.6)$ \\
\hline Metastasis (only solid tumours), $n(\%)^{\mathrm{a}}$ & $98(63.2)$ & Targeted therapy, $n(\%)^{\mathrm{j}}$ & $20(9.5)$ \\
\hline Stage III-IV (only haematological tumours), $n(\%)^{\mathrm{b}}$ & $27(65.8)$ & Other systemic treatments, $n(\%)^{\mathrm{j}}$ & $17(8.1)$ \\
\hline
\end{tabular}

ECOG Eastern Cooperative Oncology Group, $R B C$ red blood cells, $S D$ standard deviation

${ }^{\mathrm{a}}$ Valid $n=155,{ }^{\mathrm{b}}$ valid $n=41,{ }^{\mathrm{c}}$ valid $n=179,{ }^{\mathrm{d}}$ valid $n=141,{ }^{\mathrm{e}}$ valid $n=186,{ }^{\mathrm{f}}$ valid $n=188,{ }^{\mathrm{g}}$ valid $n=155,{ }^{\mathrm{h}}$ valid $n=211,{ }^{\mathrm{i}}$ valid $n=213,{ }^{\mathrm{j}}$ valid $n=210$

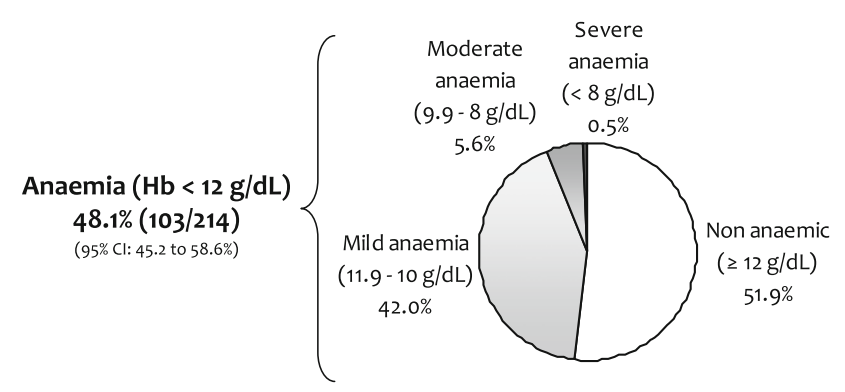

Fig. 1 Prevalence of anaemia in cancer patients treated with systemic therapy

Factors related to anaemia

There was a trend towards a higher prevalence of anaemia in women ( 52 vs. $42 \%$ in men, $p=0.140$ ) and in patients with solid tumours (52 vs. $37 \%$ in patients with haematological malignancies, $p=0.094$ ) (Fig. 2). No association between anaemia and age, stage or tumour type was observed (data not shown). A higher prevalence was found in patients with symptoms of anaemia in the last 4 weeks ( 82 vs. $40 \%$ in patients without symptoms, $p<0.0001)$, and in patients treated with CT (51 vs. $21 \%$ in patients treated with hormonal therapy or immunotherapy, $p=0.013$ ), platinumbased CT (70 vs. $47 \%$ in patients with non-platinum based $\mathrm{CT}, p=0.013$ ) or palliative CT (61 vs. $39 \%$ in patients with curative CT, $p=0.003$ ) (Fig. 2).

There were no differences in the prevalence of anaemia between patients with CT receiving monotherapy or combination therapy ( 52 vs. $49 \%, p=0.457$ ). The administration of concomitant radiotherapy was not related to anaemia either (52 vs. $48 \%, p=0.944)$.

The proportion of patients with anaemia was significantly higher in patients with more than three lines of CT (83 vs. 46, 54 and $44 \%$ in patients undergoing first-, second- and thirdline of CT, respectively, $p=0.006$ ) and in patients in the 
Table 2 Haematological parameters and symptoms of anaemia

\begin{tabular}{lll}
\hline Variable & & \\
\hline Haemoglobin $(\mathrm{g} / \mathrm{dL})$ & Valid $n$ & 214 \\
& Mean $(\mathrm{SD})$ & $12.06(1.60)$ \\
& Median & $12.0(7.4 ; 16.1)$ \\
& (range) & \\
& Valid $n$ & 214 \\
Leukocytes $\left(\times 10^{9} / \mathrm{L}\right)$ & Mean $(\mathrm{SD})$ & $5.91(2.97)$ \\
& Median & $5.0(1.6 ; 17.7)$ \\
& $($ range $)$ & \\
Platelets $\left(\times 10^{9} / \mathrm{L}\right)$ & Valid $n$ & 214 \\
& Mean $(\mathrm{SD})$ & $230.44(115.49)$ \\
& Median & $213.0(22.5 ; 927.0)$ \\
(range) & \\
During the last 4 weeks, & Valid $n$ & $206(100.0 \%)$ \\
has the patient had symptoms & Yes & $34(16.5 \%)$ \\
related to anaemia? & No & $172(83.5 \%)$ \\
In the current visit, has & Valid $n$ & $208(100.0 \%)$ \\
the patient symptoms & Yes & $35(16.8 \%)$ \\
related to anaemia? & No & $173(83.2 \%)$ \\
\hline
\end{tabular}

$S D$ standard deviation

fourth or subsequent $\mathrm{CT}$ cycles, compared with patients in the first three cycles (58 vs. $41 \%, p=0.028$ ).

No significant differences were found in mean leukocyte or platelet count between patients with and without anaemia (data not shown).
Anaemia management

In patients with anaemia $(n=103)$, the management in the previous 4 weeks was as follows: $62.1 \%$ received no specific treatment (of whom $91.9 \%$ had mild anaemia), $24.0 \%$ received ESA, $13.6 \%$ received iron supplementation and $8.7 \%$ received transfusion (Fig. 3). The use of transfusion in the previous 4 weeks was higher in patients with moderate or severe anaemia, compared to patients with mild anaemia ( 23.1 vs. $5.6 \%, p<0.0001)$. Thereby, $37.5 \%$ of patients who received transfusion during the previous 4 weeks (3 out of 8 ) still had moderate or severe anaemia.

In the current visit, the percentage of patients without any treatment for anaemia increased to $74.8 \%$ (of whom $94.9 \%$ had mild anaemia). Sixty-nine percent of the patients with moderate or severe anaemia received treatment, compared with only $18 \%$ of patients with mild anaemia $(p<0.0001)$. Only two patients were prescribed a transfusion at the study visit (one received only transfusion and the other one received transfusion, iron and ESA), both having moderate or severe anaemia.

Among the 25 patients who received any anaemia treatment at the study visit, 18 patients received ESA's (17.5\% of anaemic subjects). Darbepoetin alfa was the most commonly used agent (13 patients, four patients received epoetin beta, and 1 patient received epoetin alfa). The use of ESA's was more frequent in patients with moderate or severe anaemia (46 vs. $13 \%$ in patients with mild anaemia, $p=0.012$ ). Among patients prescribed ESA's, the mean $\mathrm{Hb}$ in patients with mild or moderate-severe anaemia was 10.5 and
Fig. 2 Prevalence of anaemia in different subgroups according to patient characteristics, type of tumour, symptoms related to anaemia and systemic therapy

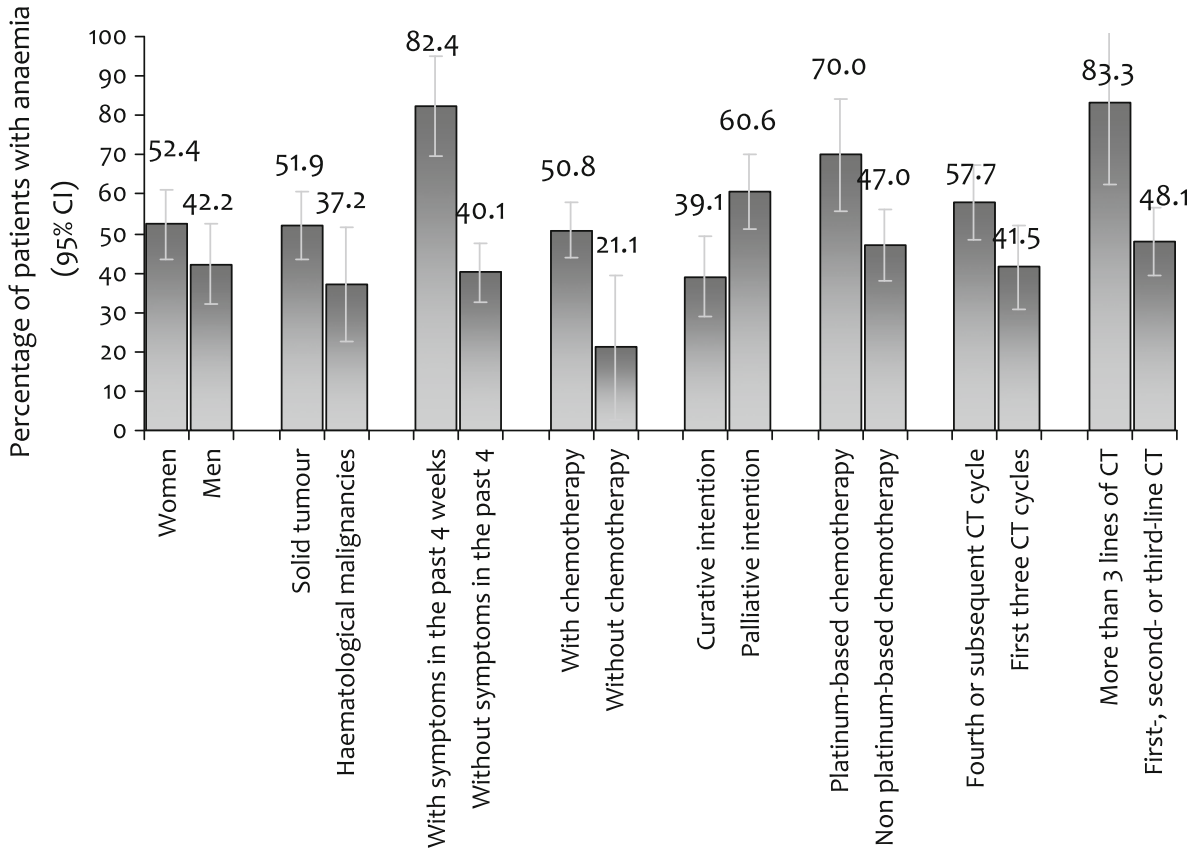



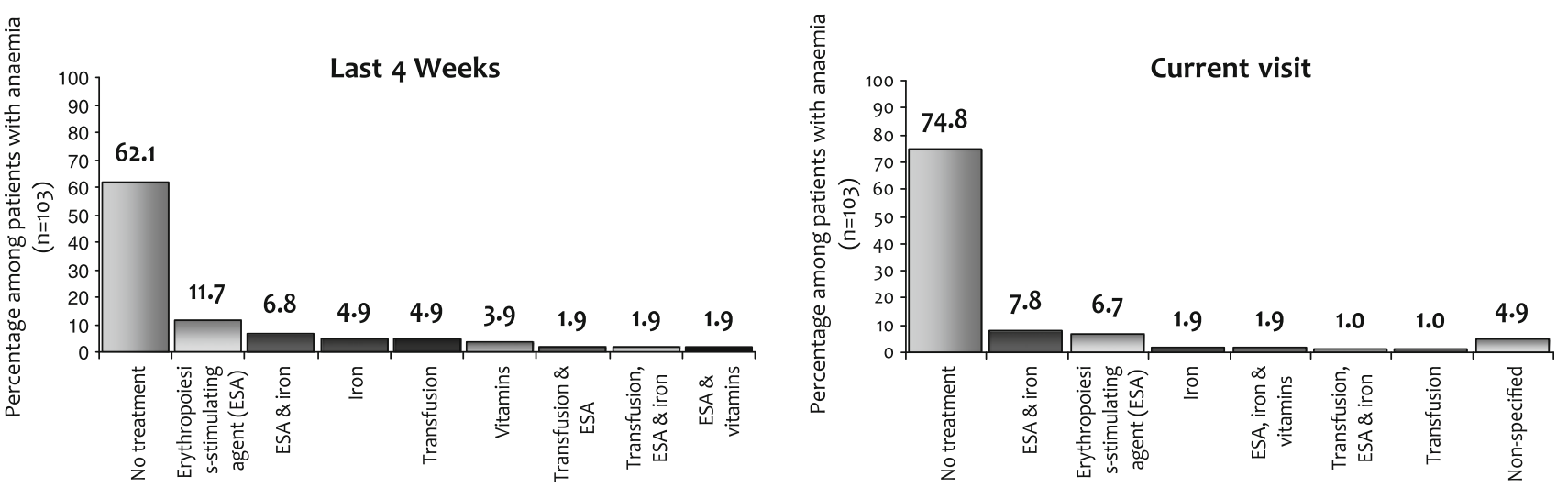

Fig. 3 Therapeutic management of anaemia (previous 4 weeks and current visit) in patients with $\mathrm{Hb}<12 \mathrm{~g} / \mathrm{dL}$ at study inclusion $(n=103)$

$8.2 \mathrm{~g} / \mathrm{dL}$, respectively. Iron supplementation was used in 13 patients (12.6\% of anaemic subjects).

\section{Discussion}

We present information on the prevalence and management of anaemia in an unselected cohort of cancer patients undergoing systemic therapy in the Spanish setting. We found a prevalence of anaemia (defined as $\mathrm{Hb}<12 \mathrm{~g} / \mathrm{dL}$ ) of approximately $50 \%$, which is similar to that found in other contemporary studies from European countries [9-11].

In the ECAS, conducted in 2001, the prevalence of anaemia at enrolment was lower (39\%), but the proportion of anaemic subjects not receiving treatment was comparable to ours (more than $60 \%$ ) [8]. Recent data from France suggest a better management of anaemia in this country, with ESA administration in approximately twothird of anaemic patients, and only $17 \%$ non-treated [9]. In the Belgian study with the same design as the present one, the prevalence of anaemia was comparable (56\%), but a higher relative proportion of moderate versus mild anaemia was found (threefold to that of the Spanish cohort) [11]. They also observed more anaemia in patients with haematological malignancies $(73 \%)$ compared to solid tumours, which disagrees with our results. The fact that they did not exclude patients with myelodysplastic syndromes (at high risk of anaemia) can partially explain this finding, but probably there are other differences involved [for example, more use of platinum-based regimens (37 vs. $26 \%$ in our cohort), or more proportion of advanced disease]. Regarding anaemia management, there were also important disparities with our results: a higher proportion of treated patients (almost $50 \%$ ) and more transfusions. Iron use was similar [11].

We observed a strong association between CT administration and anaemia, as previously reported in the ECAS
[12]. Among CT-related factors, more than three lines of treatment or more than three cycles were associated to a higher risk of anaemia. Similarly, during ECAS, the prevalence of anaemia increased progressively from cycle 1 to cycle 6 [13]. The observed association with palliative CT probably reflects the degree of severity of the disease and its impact on erythropoiesis. Interestingly, the prevalence of anaemia was not different in patients receiving mono-CT as opposed to poly-CT, but it was higher in patients receiving platinum-based regimens (70 vs. $47 \%$ ). We did not find any significant influence of radiotherapy administration. A model developed by Barret et al. [14] to predict anaemia development in cancer patients initiating CT included the following variables as the most important factors: low initial $\mathrm{Hb}(\leq 12.9 \mathrm{~g} / \mathrm{dL}$ in females, and $\leq 13.4 \mathrm{~g} / \mathrm{dL}$ in males); cancer type other than gastrointestinal/colorectal cancer; treatment with platinum CT, and female gender. We did not analyze the prevalence by tumour subtype, due to sample size limitation, but we confirm a strong association with platinum-based CT.

Since ECAS, several guidelines have provided recommendations for ESA use in cancer patients. The EORTC [6] guidelines recommend to treat all patients with $\mathrm{Hb}$ levels below $9 \mathrm{~g} / \mathrm{dL}$ (who were only a small percentage of our sample), and all symptomatic patients with levels between 9 and $11 \mathrm{~g} / \mathrm{dL}$. The Anaemia Cancer Treatment (A.C.T.) study was a retrospective, extensive review of anaemic patients with cancer treated with ESAs investigating patterns of use according to EORTC guidelines [15]. It concluded that, in 2007, most European patients were treated per guidelines, except for low iron supplementation rates [16]. A prospective German study in cancer patients with anaemia observed that physicians preferred ESA as first-line treatment in patients with solid tumours, but in patients with lymphoproliferative malignancies, transfusions or correction of underlying disorders was preferred. They also reported underuse of intravenous iron therapy [10]. In our cohort, around one-third of anaemic subjects 
were symptomatic, which means that at least the same amount of individuals would benefit from receiving ESAs. Since only $17 \%$ of patients were being treated with erythropoietic agents, we can conclude that the EORTC guidelines were still not fully implemented during 2008 in the clinical practice of Spanish Oncology or Oncohematology services. Current guidelines of the Spanish Society of Medical Oncology (SEOM) about the use of ESAs in cancer patients [17] were published in 2009, after the study completion. They established that, since ESA treatment increases the $\mathrm{Hb}$ level and decreases the red blood cell transfusion requirements, ESAs should be used within the approved indications in patients undergoing chemotherapy treatment, beginning at an $\mathrm{Hb}$ level below $11 \mathrm{~g} / \mathrm{dL}$ and maintaining it around $12 \mathrm{~g} / \mathrm{dL}$, with iron supplements if necessary. Thus, our data also shows that management of anaemia in Spain needs to be updated according to local guidelines.

Despite the concerns about use of ESAs, all metaanalyses considering only clinical trials performed under the approved indication (patients receiving chemotherapy) support their safety and clinical benefit in the treatment of chemotherapy-induced anaemia [18-23], including a reduction in transfusion needs both in solid tumours and in haematological malignancies $[24,25]$. In the larger metaanalysis conducted until now, the use of ESAs was neutral with regard to survival and disease progression [26]. In this meta-analysis, it was also demonstrated that the use of ESAs is associated with an increased risk of venous thromboembolism (odds ratio $=1.4$ ) [26]. Regarding the increase in the risk for thromboembolic events [23, 27], it must be taken into account specially in patients with cardiovascular disease, in whom the ESA dose must be adjusted according to patient characteristics to avoid an excessive change in plasma volume and maintaining a consistent $\mathrm{Hb}$ level [28].

The main limitations of our study are the limited sample size, that does not allow to explore differences in the prevalence and management of anaemia between tumour subtypes, for example, and the cross-sectional design, which does not allow for causal inferences.

\section{Conclusion}

In Spanish hospitals, about half of patients with nonmyeloid malignancies undergoing systemic therapy suffer from anaemia. Chemotherapy administration, especially if it contains platinum compounds or represents an advanced-line therapy, is associated with a high risk of anaemia. Our results show that approximately two-third of patients with anaemia do not receive specific treatment and that ESAs are underused according to current
EORTC and local SEOM guidelines. Since the treatment of anaemia with ESAs (and adequate iron supplementation) can significantly improve patients' quality of life and may also improve the clinical outcome, it is advisable to review and optimize anaemia management in the clinical practice of Spanish Oncology and Hematology services.

Acknowledgments This study was supported in part by a grant from Amgen, S.A. The medical writing support was also funded by Amgen S.A. Writing assistance was provided by Dr. Neus Valveny from Trial Form Support. All the authors have full control of all primary data and agree to allow the journal to review the data if requested.

Conflict of interest JLS is consultant for Novartis, BMS, Pfizer and Amgen, and has received funding from Novartis and BMS. The other authors declare no conflict of interest.

Open Access This article is distributed under the terms of the Creative Commons Attribution License which permits any use, distribution, and reproduction in any medium, provided the original author(s) and the source are credited.

\section{Appendix}

The following investigators are members of the ANAEMIA DAY Study Group and also participated in this study: Co-authors. This study has been conducted by the abovesigned authors and the ANAEMIA DAY study group: Dra. Carmen Crespo; Dr. Javier López; Dr. J. Sánchez Torres; Dr. Ramón Colomer; Dra. Ángeles Vaz; Dr. Ignacio Jalón; Dr. Mariano Provencio; Dra. Mar Pérez; Dr. Jaime Pérez; Dr. J. L. Steegmann; Dr. J. A. Arranz y Dr. Luís Cabezón; Dr. Carlos Grande; Dra. Ana I. Ballesteros; Dr. Javier Puente; Dra. Concha López; Dra. Anabelle Chinea y Dr. Valentín Gutiérrez; Dr. Pedro Salinas y Dr. Pérez Carrión; Dra. Raquel de Paz y Dra. Ana López; Dr. Ignacio García E; Dra. Pilar Samper; Dr. J. A. García Saénz.

\section{References}

1. Groopman JE, Itri LM (1999) Chemotherapy-induced anemia in adults: incidence and treatment. J Natl Cancer Inst 91:1616-1634

2. Demetri G (2001) Anaemia and its functional consequences in cancer patients: current challenges in management and prospects for improving therapy. $\mathrm{Br} \mathrm{J}$ Cancer 84:31-37

3. Caro JJ, Salas M, Ward A, Goss G (2001) Anemia as an independent prognostic factor for survival in patients with cancer. Cancer 91:2214-2221

4. Van Belle SJP, Cocquyt V (2003) Impact of haemoglobin levels on the outcome of cancers treated with chemotherapy. Crit Rev Oncol Hematol 47:1-11

5. Rizzo JD, Somerfield MR, Hagerty KL, Seidenfeld J, Bohlius J, Bennett CL, Cella DF, Djulbegovic B, Goode MJ, Jakubowski AA, Rarick MU, Regan DH, Lichtin AE (2008) Use of epoetin and darbepoetin in patients with cancer: 2007 American Society of Clinical Oncology/American Society of Hematology clinical practice guideline update. J Clin Oncol 26:132-149

6. Aapro MS, Link H (2008) September 2007 update on EORTC guidelines and anemia management with erythropoiesis-stimulating agents. Oncologist 13(Suppl 3):33-36 
7. Scrijvers D, Roila F (2009) Erythropoiesis-stimulating agents in cancer patients: ESMO recommendations for use. Ann Oncol 20(Suppl 4):159-161

8. Ludwig H, Van Belle S, Barrett-Lee P, Birgegard G, Bokemeyer C, Gascon P, Kosmidis P, Krzakowski M, Nortier J, Olmi P, Schneider M, Schrijvers D (2004) The European Cancer Anaemia Survey (ECAS): a large, multinational, prospective survey defining the prevalence, incidence, and treatment of anaemia in cancer patients. Eur J Cancer 40:2293-2306

9. Guardiola E, Morschhauser F, Zambrowski JJ, Antoine EC (2007) Prise en charge de l'anemie chez les patients presentant une pathologie maligne: resultats de l'etude F-ACT (French Anaemia Cancer Treatment). Bull Cancer 94:907-914

10. Steinmetz T, Totzke U, Schweigert M, Mittermuller J, Nawka S, Tesch H, Groschek M, Soling U, Hellebrand E, Tsamaloukas A (2011) A prospective observational study of anaemia management in cancer patients-results from the German Cancer Anaemia Registry. Eur J Cancer Care (Engl) 20:493-502

11. Verbeke N, Beguin Y, Wildiers H, Canon JL, Bries G, Bosly A, Van Belle S (2012) High prevalence of anaemia and limited use of therapy in cancer patients: a Belgian survey (Anaemia Day 2008). Support Care Cancer 20:23-28

12. Birgegard G, Aapro MS, Bokemeyer C, Dicato M, Drings P, Hornedo J, Krzakowski M, Ludwig H, Pecorelli S, Schmoll H, Schneider M, Schrijvers D, Shasha D, Van Belle S (2005) Cancer-related anemia: pathogenesis, prevalence and treatment. Oncology 68(Suppl 1):3-11

13. Kosmidis P, Krzakowski M (2005) Anemia profiles in patients with lung cancer: what have we learned from the European Cancer Anaemia Survey (ECAS)? Lung Cancer 50:401-412

14. Barrett-Lee PJ, Ludwig H, Birgegard G, Bokemeyer C, Gascon P, Kosmidis PA, Krzakowski M, Nortier JW, Kongable G, Schneider M, Schrijvers D, Van Belle SJ (2006) Independent risk factors for anemia in cancer patients receiving chemotherapy: results from the European Cancer Anaemia Survey. Oncology 70:34-48

15. Aapro M, Abraham I, Bokemeyer C, Ludwig H, Macdonald K, Soubeyran P, Turner M (2008) The background and methodology of the Anaemia Cancer Treatment (A.C.T.) study: a global retrospective study of practice patterns and outcomes in the management of anaemia in cancer patients and their congruence with evidence-based guidelines. Support Care Cancer 16:193-200

16. Ludwig H, Aapro M, Bokemeyer C, Macdonald K, Soubeyran P, Turner M, Albrecht T, Abraham I (2009) Treatment patterns and outcomes in the management of anaemia in cancer patients in Europe: findings from the Anaemia Cancer Treatment (ACT) study. Eur J Cancer 45:1603-1615

17. Alberola Candel V, Carrato Mena A, Diaz-Rubio Garcia E, Gascon Vilaplana P, Gonzalez Baron M, Martin Jimenez M, Alba Conejo E, Cassinello Espinosa J, Colomer R, Cruz Hernandez JJ, Barnadas i Molins A, Camps Herrero C, Casas Fernandez de Tejerina AM, Carulla Torrent J, Constenla Figueiras M, Gavila Gregori J, Isla Casado MD, Massuti Sureda B, Provencio Pulla M, Rodriguez Sanchez CA, Sanz Ortiz J (2009) Spanish Society of Medical Oncology consensus on the use of erythropoietic stimulating agents in anaemic cancer patients. Clin Transl Oncol 11:727-736
18. Aapro M, Scherhag A, Burger HU (2008) Effect of treatment with epoetin-beta on survival, tumour progression and thromboembolic events in patients with cancer: an updated meta-analysis of 12 randomised controlled studies including 2301 patients. Br J Cancer 99:14-22

19. Bohlius J, Schmidlin K, Brillant C, Schwarzer G, Trelle S, Seidenfeld J, Zwahlen M, Clarke M, Weingart O, Kluge S, Piper M, Rades D, Steensma DP, Djulbegovic B, Fey MF, Ray-Coquard I, Machtay M, Moebus V, Thomas G, Untch M, Schumacher M, Egger M, Engert A (2009) Recombinant human erythropoiesis-stimulating agents and mortality in patients with cancer: a metaanalysis of randomised trials. Lancet 373:1532-1542

20. Hedenus M, Vansteenkiste J, Kotasek D, Austin M, Amado RG (2005) Darbepoetin alfa for the treatment of chemotherapy-induced anemia: disease progression and survival analysis from four randomized, double-blind, placebocontrolled trials. J Clin Oncol 23:6941-6948

21. Ross SD, Allen IE, Henry DH, Seaman C, Sercus B, Goodnough LT (2006) Clinical benefits and risks associated with epoetin and darbepoetin in patients with chemotherapy-induced anemia: a systematic review of the literature. Clin Ther 28:801-831

22. Wauters I, Vansteenkiste J (2009) Darbepoetin alfa in the treatment of chemotherapy-induced anaemia. Expert Opin Biol Ther 9:221-230

23. Ludwig H, Crawford J, Osterborg A, Vansteenkiste J, Henry DH, Fleishman A, Bridges K, Glaspy JA (2009) Pooled analysis of individual patient-level data from all randomized, double-blind, placebo-controlled trials of darbepoetin alfa in the treatment of patients with chemotherapy-induced anemia. J Clin Oncol 27:2838-2847

24. Bohlius J, Wilson J, Seidenfeld J, Piper M, Schwarzer G, Sandercock J, Trelle S, Weingart O, Bayliss S, Djulbegovic B, Bennett CL, Langensiepen S, Hyde C, Engert A (2006) Recombinant human erythropoietins and cancer patients: updated meta-analysis of 57 studies including 9353 patients. J Natl Cancer Inst 98:708-714

25. Wilson J, Yao GL, Raftery J, Bohlius J, Brunskill S, Sandercock J, Bayliss S, Moss P, Stanworth S, Hyde C (2007) A systematic review and economic evaluation of epoetin alpha, epoetin beta and darbepoetin alpha in anaemia associated with cancer, especially that attributable to cancer treatment. Health Technol Assess 11:1-202, iii-iv

26. Glaspy J, Crawford J, Vansteenkiste J, Henry D, Rao S, Bowers P, Berlin JA, Tomita D, Bridges K, Ludwig H (2010) Erythropoiesis-stimulating agents in oncology: a study-level meta-analysis of survival and other safety outcomes. $\mathrm{Br}$ J Cancer 102:301-315

27. Wun T, Law L, Harvey D, Sieracki B, Scudder SA, Ryu JK (2003) Increased incidence of symptomatic venous thrombosis in patients with cervical carcinoma treated with concurrent chemotherapy, radiation, and erythropoietin. Cancer 98:1514-1520

28. Aapro M (2009) An update on twenty years of anemia management with erythropoiesis-stimulating agents in nephrology and oncology/hematology. Oncologist 14(Suppl 1):1-5 